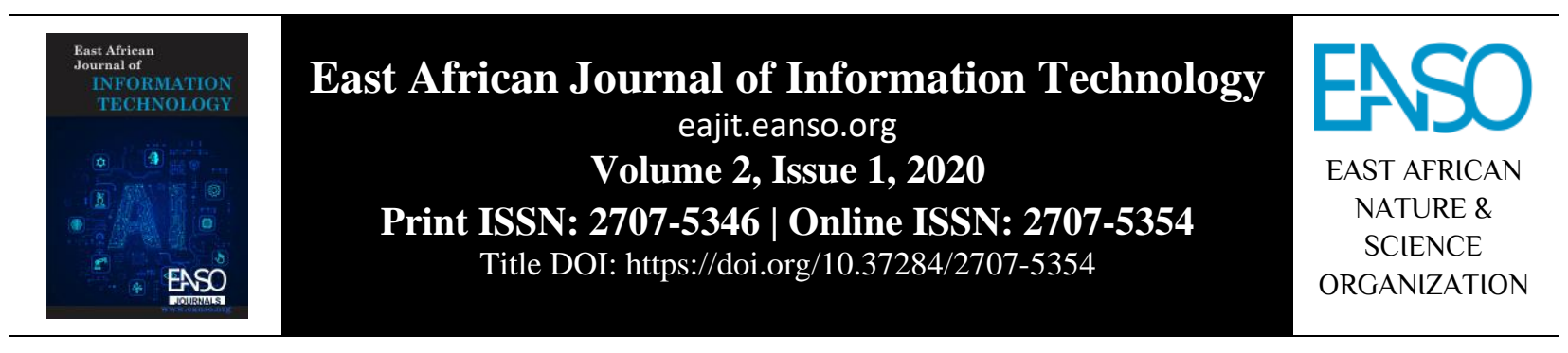

Original Article

\title{
The Evolution of GSM Technologies into 5G and the Imminent Emergence of Transformative Telemedicine Applications: A Review
}

\author{
Nixon Amuomo* \\ Rongo University, P. O. Box 103 - 40404, Rongo, Kenya. \\ *Correspondence email: namuomo@gmail.com.
}

Article DOI: https://doi.org/10.37284/eajit.2.1.131

\section{Article history:}

Received: 19 Nov 2019

Accepted: 26 Nov 2019

Published: 06 Apr 2020

Keywords:

Telemedicine,

Telediagnostics, Artificial Intelligence, Biomedical Images,

Pattern Matching.

\section{ABSTRACT}

Telemedicine is the delivery of health care services over a distance by health care providers using electronic technologies for the diagnosis, information exchange, treatment and disease prevention, injuries prevention, research and evaluation, and for continuing education for the health care provider. Telemedicine has been in existence since the 1960s, through telephone and video technologies. Over several decades, wireless broadband technology has become better with advancement with internet speed becoming almost ubiquitous. According to a telemedicine study by World Health Organization, 114 countries, that is, $(59 \%)$ of member states, revealed that teleradiology has the highest rate of established service provision globally at (33\%). Close to $70 \%$ of the countries indicated the need to know the cost and cost-effectiveness of telemedicine solutions, and above 50\% needed to know about the infrastructure needed for telemedicine implementation while $60 \%$ needed clarification on clinical uses. With the evolution of Global System for Mobile (GSM) Communication services into 5G, it is the objective of this study to demonstrate how a combination of faster communication at lower latencies can be used to provide clinical support that overcomes geographical barriers using Information and Communication Technologies (ICT), with a goal of transforming healthcare service provision. A resultant prototype telemedicine application capable of medical diagnosis using artificial intelligence techniques demonstrates with the highest accuracy at 93.68\% match. The medical similarity index of pathogens is captured from digital sources such as USB microscopes and scanners as medical images or specimens. 


\section{APA CITATION}

Amuomo, N. (2020). The Evolution of GSM Technologies into 5G and the Imminent Emergence of Transformative Telemedicine Applications: A Review. East African Journal of Information Technology, 2(1), 8-16. https://doi.org/10.37284/eajit.2.1.131

\section{CHICAGO CITATION}

Amuomo, Nixon. 2020. "The Evolution of GSM Technologies into 5G and the Imminent Emergence of Transformative Telemedicine Applications: A Review". East African Journal of Information Technology 2 (1), 8-16. https://doi.org/10.37284/eajit.2.1.131.

\section{HARVARD CITATION}

Amuomo, N. (2020) "The Evolution of GSM Technologies into 5G and the Imminent Emergence of Transformative Telemedicine Applications: A Review", East African Journal of Information Technology, 2(1), pp. 8-16. doi: 10.37284/eajit.2.1.131.

\section{IEEE CITATION}

N. Amuomo, "The Evolution of GSM Technologies into 5G and the Imminent Emergence of Transformative Telemedicine Applications: A Review", EAJIT, vol. 2, no. 1, pp. 8-16, Apr. 2020.

\section{INTRODUCTION}

Information and Communications Technologies (ICT) offers great potential in addressing some of the challenges of Universal Health Care (UHC) delivery in developing countries. The use of ICT and other technologies in the health sector has given birth to the concepts of Telemedicine, Telehealth, Telecare, mHealth, eHealth and digital health, which are often used interchangeably (Norris \& Morgan, 2002). The absence of alternatives to health care delivery in relation to accessibility and geographical disparities of healthcare facilities are some of the reasons why ICT implementation is necessary (Craig \& Patterson, 2005). Based on the ICT potential, the World Health Organization (WHO) established the Global Observatory for eHealth (GOe) to review the benefits of ICTs in the health care sector for patients' wellbeing (Kay, Santos \& Takane, 2010).

The term 'Telemedicine' was coined in the 1970s, to mean "healing at a distance" and it signified the use of ICT to improve patient outcomes by enabling healthcare and medical information access (Strehle \& Shabde, 2006). The first published evidence of telemedicine can be tracked in the 20th century denoted by the transmission of electrocardiograph data over telephone wires (Strehle \& Shabde, 2006). The modern Telemedicine, therefore, started in the 1960s largely driven by the military and space technologies (Kay, Santos \& Takane, 2010).
For example, the use of television to facilitate cross consultation between psychiatric institute specialists and the general practitioners at a state mental hospital. The rapid technological revolution from analogue communication channels to digital channels combined with drops in the cost of ICT has caused increased interests in telemedicine application by health care providers. The advent of the internet has further accelerated ICT advancements to exceeding heights such as webbased applications like e-mail, teleconsultations via the internet, and multimedia approaches such as medical imagery (Figure 1) and video. These, therefore, have led to exciting interests in the advancement of telemedicine applications that the developing countries may leverage on.

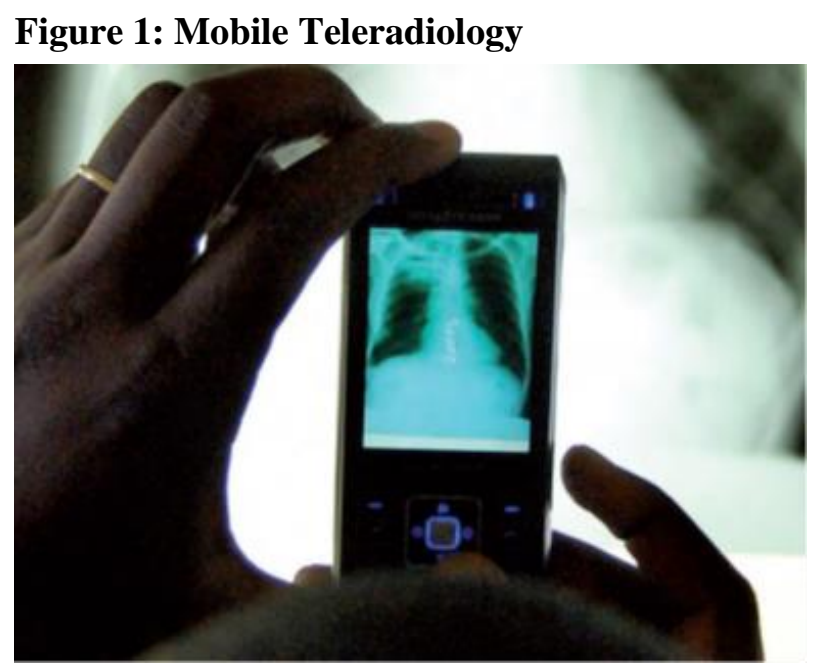

Source: (Kay, Santos \& Takane, 2010). 
Human health is the key to human development and progress. Therefore, with a dysfunctional healthcare system, stakeholders are seeking ways in which they can ensure that universal health coverage is achieved. In a broader perspective, the fundamental objective of telemedicine is to improve the health of the people. The use of modern information technologies is to help integrate and coordinate the healthcare service delivery to ensure that there are improved patient outcomes (patientcentric), in terms of greater efficiencies, higher transparency levels and improved ease of access of services (Crock, 2016). Another issue is that healthcare is not personalized and doctors can prescribe medication based on population averages with very minimum data-driven strategies. It becomes even more costly to provide tailor-made treatment based on patient medical history. Accessibility of healthcare facilities is another notable challenge faced by the developing countries, more so, for patients from marginalised cadres such as persons with disabilities. The purpose of this paper was to illustrate how GSM evolution technologies in a multi-device environment enable telemedicine through the internet of things (IoT), artificial intelligence (AI) and machine learning (ML) and how it will restructure healthcare system in the near future.

$5 \mathrm{G}$ refers to the fifth generation of wireless transmission technology. some of the important characteristics of $5 \mathrm{G}$ technology are good data transfer rates, latency, coverage, power and network energy usage with unique characteristics of high-speed data transfer rate, super-low latency (delay in the data transmission-response system), connectivity and capacity, and high bandwidth and durability per unit area, that is good for the healthcare sector ( $\mathrm{Li}, 2019)$. Using 5G super bandwidth and the capacity to connect devices in an ecosystem in an intelligent network, 5G will serve as real-time interactivity for equipment and patients using speed, latency, coverage, availability and low power IoT services trade-off's (Li, 2019). Figure 2 below illustrates some applications of $5 \mathrm{G}$ technology in healthcare.

Figure 2: Applications of 5G technology in healthcare.

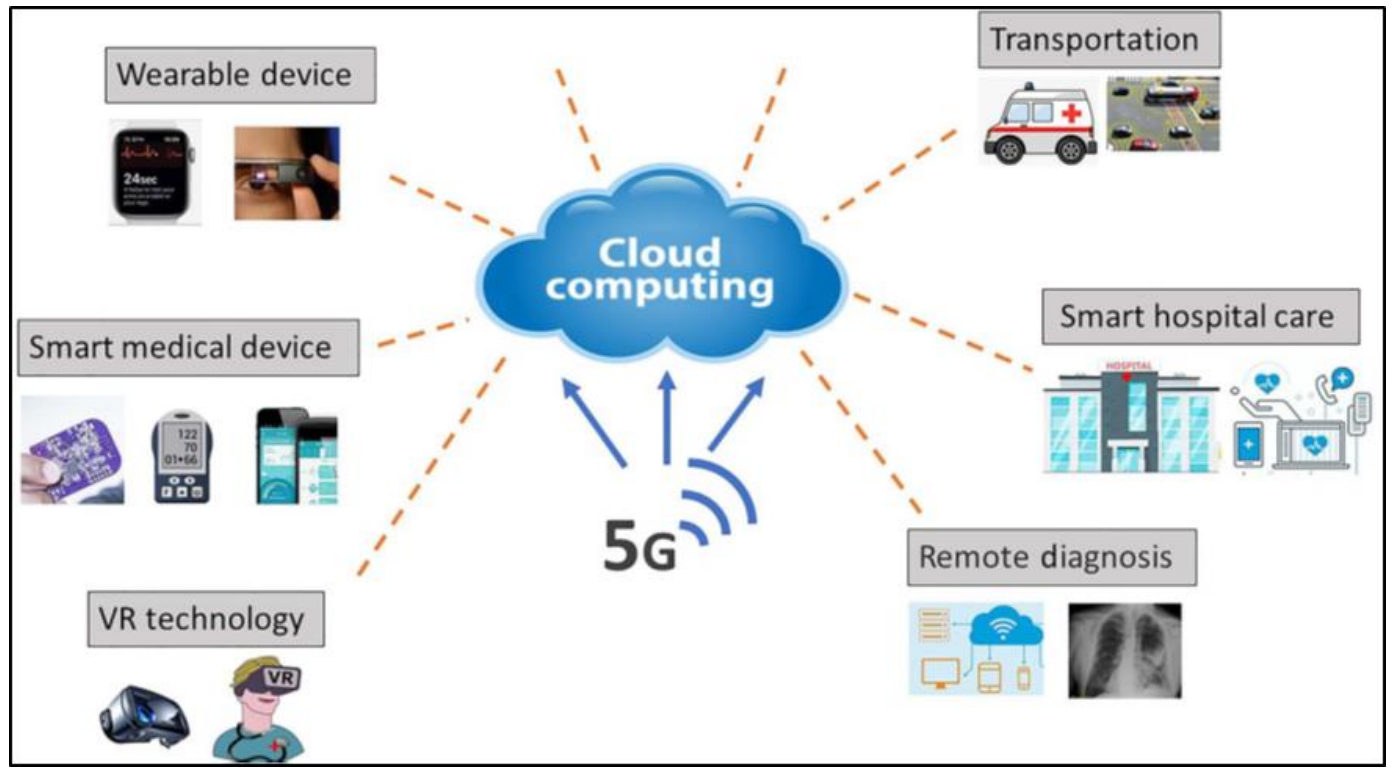

Source: (Li, 2019)

The objective of this paper was to systematically review the literature on GSM evolution and its appropriateness as an enabler to telemedicine. The paper demonstrates how a combination of faster network communication and devices performing at lower latencies can be used to provide clinical support that overcomes geographical barriers using ICT through artificial intelligence telemedicine application capable of medical diagnosis. 


\section{The Mobile Transmission Evolution}

Mobile communication has become more popular in the last few years due to the fast internet advancements from $1 \mathrm{G}$ to $5 \mathrm{G}$ in the mobile technology field. This reform is driven by compatible service transmission technologies such as increased numbers of telecoms customers. With the mobile cellular era starting in the 1980s, it has undergone a considerable change and massive growth (Meraj \& Kumar, 2015). It is believed that with the coming of a $5 \mathrm{G}$ network, personal communication in a fully digital society will be addressed. The combination of faster communication speeds with low latencies (1 Gbps speeds and <10 ms latency) has the potential to transform healthcare through the provision of more robust datasets. This robustness seen in 5G communication is a precursor to the healthcare revolution. As per the previous trends of the societal transformation of $2 \mathrm{G}, 3 \mathrm{G}$, and $4 \mathrm{G}, 5 \mathrm{G}$ will escalate these successes in supporting existing services and new services with new automation business models in an intelligent manner (Husenovic, Bedi \& Maddens, 2018). The table below shows the mobile networks deployment dates, evolution speeds and latency.

Table 1: Evolution of mobile networks

\begin{tabular}{llllll}
\hline & $\mathbf{1 G}$ & $\mathbf{2 G}$ & $\mathbf{3 G}$ & $\mathbf{4 G}$ & $\mathbf{5 G}$ \\
\hline Approximate deployment date & $1980 \mathrm{~s}$ & $1990 \mathrm{~s}$ & $2000 \mathrm{~s}$ & $2010 \mathrm{~s}$ & $2020 \mathrm{~s}$ \\
Theoretical download speed & $2 \mathrm{kbit} / \mathrm{s}$ & $384 \mathrm{kbit} / \mathrm{s}$ & $56 \mathrm{Mbit} / \mathrm{s}$ & $1 \mathrm{Gbit} / \mathrm{s}$ & $10 \mathrm{Gbit} / \mathrm{s}$ \\
Latency & N/A & $629 \mathrm{~ms}$ & $212 \mathrm{~ms}$ & $60-98 \mathrm{~ms}$ & $<1 \mathrm{~ms}$ \\
\hline
\end{tabular}

Source: (Husenovic, Bedi \& Maddens, 2018)

According to GSMA, the mobile transition into 5G is to provide boundless connectivity for all while delivering network innovativeness for optimal economics. Accelerated digital transformation across industry verticals through the transformed mobile broadband will drive the growth of the Internet of things (IoT) and critical communication services. Table 2 below shows the paradigm shifts between cellular generations and their service impacts. The technology moves from $4 \mathrm{G}$ to $\mathrm{Wi}-\mathrm{Fi}$ and $\mathrm{Wi}-\mathrm{Fi}$ to $\mathrm{LiFi}$. LiFi is an optical wireless broadband access technology that uses visible and infrared light spectrum in providing bi-directional transmission capability.

Table 2: 5G Paradigm shift into RF-LiFi Spectrum

\begin{tabular}{llll}
\hline Cellular Generations & Paradigm Shifts & Service Pull & Impact \\
\hline $1 \mathrm{G} \rightarrow 2 \mathrm{G}$ & Analogue to digital & Mobile telephony & Revolution \\
$2 \mathrm{G} \rightarrow 3 \mathrm{G}$ & Small cell concept & Mobile internet & Evolution \\
$3 \mathrm{G} \rightarrow 4 \mathrm{G}$ & Small cell concept & Mobile internet & Evolution \\
$4 \mathrm{G} \rightarrow 5 \mathrm{G}$ & Multi-Access Network & Machine to machine communications & Evolution \\
Beyond 5G New radio & RF to light (LiFi) & LaaS, IoT and eMBB & Revolution \\
\hline
\end{tabular}

Source: (Sodhro \& Shah, 2017).

\section{Current Health Care Systems Challenges}

Many organizations invest hugely in Information technology which has complex implementation processes, with lots of dynamics that could lead to implementation failures resulting into enormous time, effort, financial wastages, and risks to lives (Justice, 2012).
A great part of the population percentage who stay in rural areas, find it difficult to access specialists for good quality health attention at the right time. The specialists are usually located in town areas with a number of them covering only $20 \%$ of the population. As per the eHealth strategy report 2011$2017,80 \%$ of clinicians serve $20 \%$ of the population. In as much as medical specialists are concentrated in urban centres and health care infrastructure suffers from imbalances in the 
regions and urban to rural areas with personnel shortage and lack of investment for this coverage. Table 3 below shows personnel-to-patient ratios as per the Kenya eHealth strategy report 2011-2017 (MOMS \& MOPHS, 2011). The huge imbalance between the patient and doctor ratio points to a desperate health care system. According to Watts et al, (2005), some of the challenges bedevilling healthcare in developing countries are so critical such as chronic illnesses, lack equipped amenities, and lack of enough skilled personnel.

Table 3: Personnel-Patient Ratio of Kenya

\begin{tabular}{lrc}
\hline Workforce & Total & Approximate ratio of workforce per patient \\
\hline Doctors & 1513 & $1: 26438$ \\
Dentists & 169 & $1: 236686$ \\
Pharmacists & 283 & $1: 141343$ \\
Clinical Officers - CO's & 2104 & $1: 19011$ \\
Nurses & 16227 & $1: 2465$ \\
Other Health Staff & 9720 & $1: 4115$ \\
Non-Health Staff & 5615 & $1: 7124$ \\
Overall & 35631 & \\
\hline
\end{tabular}

Source: (MOMS \& MOPHS, 2011)

WHO recommend minimum staffing levels of 2.3 practitioners per 1,000 populations while Kenya practitioners staffing levels are at 1.5 per 1,000 population. In order to achieve the WHO recommended levels, there is a need to increase the number of health care practitioners by $53 \%$ (WHO, 2006).

Financials are also a challenge for the health sector and it is a risk in the rolling out of health-related information systems projects in third world countries. This is according to a study carried out by Pal et al. (2005), Xue and Liang (2007). The invent of 5G technology will not only help in providing cheap connectivity but will also aid in limiting costs related to transport, onsite staff training to online training and related health information systems innovations. 5G technology enabling telemedicine will aid in realizing universal health coverage (UHC) as evidenced in the national eHealth strategy policy paper report of 2011-2017, which identified ICT as a key driver for the improvement of healthcare outcomes. According to the Kenya National eHealth policy 2016-2030, successful eHealth systems such as telemedicine implementations are hindered by poor infrastructure, low literacy, inadequate technical expertise, unreliable power supply, limited funding, and lack of government involvement in most eHealth projects.
Infrastructure such as those that support the utilization of current internet technologies as well as supporting the operations of any health-related ICT project remains a constraint (WHO, 2010). Developing countries still have infrastructure challenges such as internet connectivity, which is still a problem (Kay, Santos \& Takane, 2010).

\section{The Role of Technology in Closing Healthcare Delivery Gaps}

Technology disruption of the industry stems from the theory of disruptive innovation introduced by Christensen (2013). The theory provided clarification on the displacement of industry giants by lesser competitors and opening up channels for new entrants (Giovanisa \& Athanasopouloub, 2018). Disruptive is a term used in the business and information technology literature to describe innovations that improve products or services and later lowering the cost of doing business to clients (Appiah, Ozuem \& Howell, 2019).

The digital transformation happening in the healthcare industry will be as disruptive as that seen already in other sectors (Klewes, Popp \& RostHein, 2016; Valenduc \& Vendramin, 2017). The traditional way of health care service provision is slowly being invaded by artificial intelligence, machine learning and internet of doing things. 
Healthcare systems running on AI, machine learning, or probabilistic models could provide therapeutic recommendations, prognosis learning, and real-time disease scoring. Diagnosis and treatment are today partially performed by medical histories and symptoms of the patient. ICT can perform better diagnosis and treatments by utilizing complex physiological and sensor data than a healthcare provider. It has also been argued that computers will replace $80 \%$ of what doctors can do in the future while providing accurate and factbased clinical recommendations in a quicker way (Khosla, 2012).

The potential use of $5 \mathrm{G}$ technology (ICT) in healthcare in resources constrained environments such as the developing countries, has been emphasized by the World Health Organization report (WHO, 2010). For instance, telemedicine projects will help meet hitherto unmet health needs (Brandling-Bennett et al., 2005), thus impacting significantly and positively on healthcare. Telemedicine offers pragmatic opportunities for distant health care delivery in areas of evaluation, diagnosis, treatments and follow-ups (Croteau et al., 2005). It also offers an opportunity for patients to seek early treatment and to adhere to treatment schedules, thereby improving patient quality of life, reducing patient referrals, reducing travel cost and

\section{Figure 3: Mobile telemedicine app}

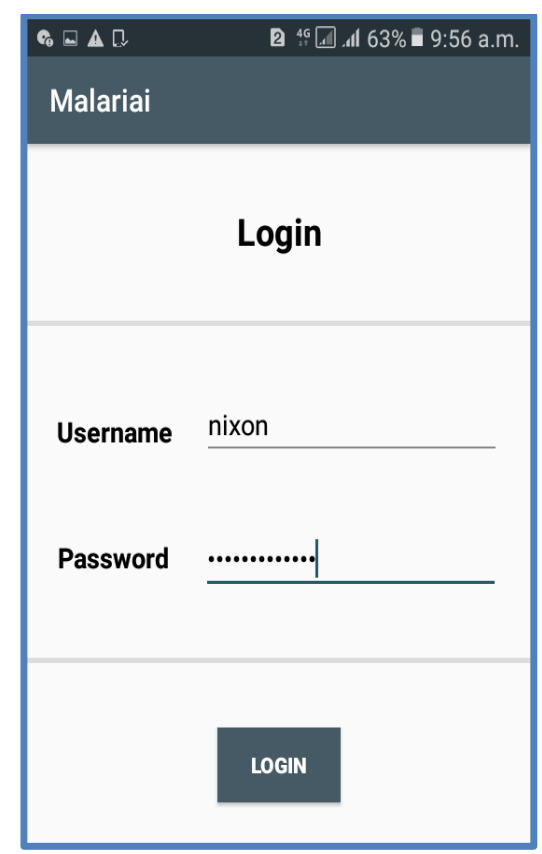

stress through information technology access. The provision of telemedicine services may also motivate health professionals to stay in remote health facilities, because of the support they will enjoy from the other health practitioners (Gagnon et al, 2006), thus providing a source of reassurance to both health professionals and patients in remote areas (WHO, 2010).

To demonstrate the use of telemedicine using GSM technology a mobile application software was developed with the capability of analyzing medical images, in a multi distributed telecommunications environment. Using artificial intelligence (AI) techniques of pattern recognition (that is, finding and extracting specific patterns in a given image), it has been shown that, with the evolution of GSM Technologies into $5 \mathrm{G}$, a robust telemedicine capability can be a reality. Figure 3 below, shows login screen to the mobile app, were different medical images (specimens), can be uploaded for similarity analysis. The resultant specimen comparison between parasite A and parasite B is 93.68\% similar. This implies that the two specimens are closely matching. Assuming parasite $\mathrm{A}$, is positive (primary) and parasite B is the new upload (under investigation), we can deduce that parasite $\mathrm{B}$ is also positive.

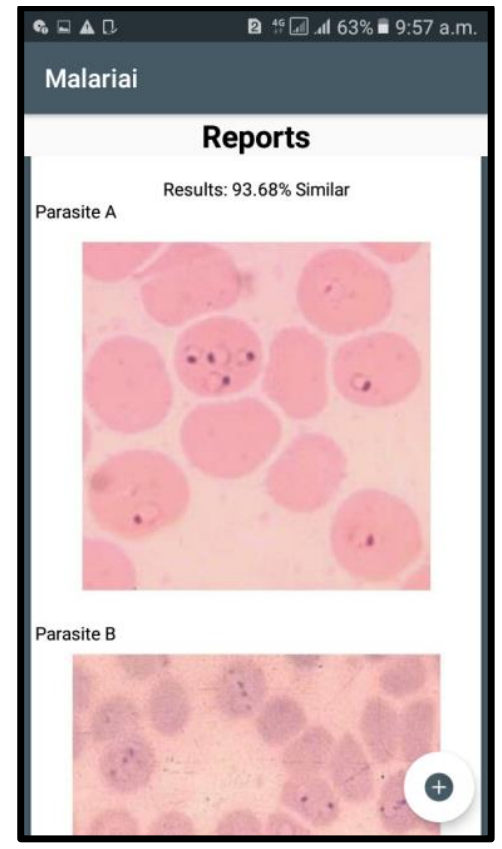


Figure 4 below shows a comparison of two specimen images with slightly different stains. The analysis of the two samples for similarity is $73.98 \%$, meaning the two specimens are slightly different as per the AI algorithms used.

Figure 4: Comparison of two medical images for similarity - A

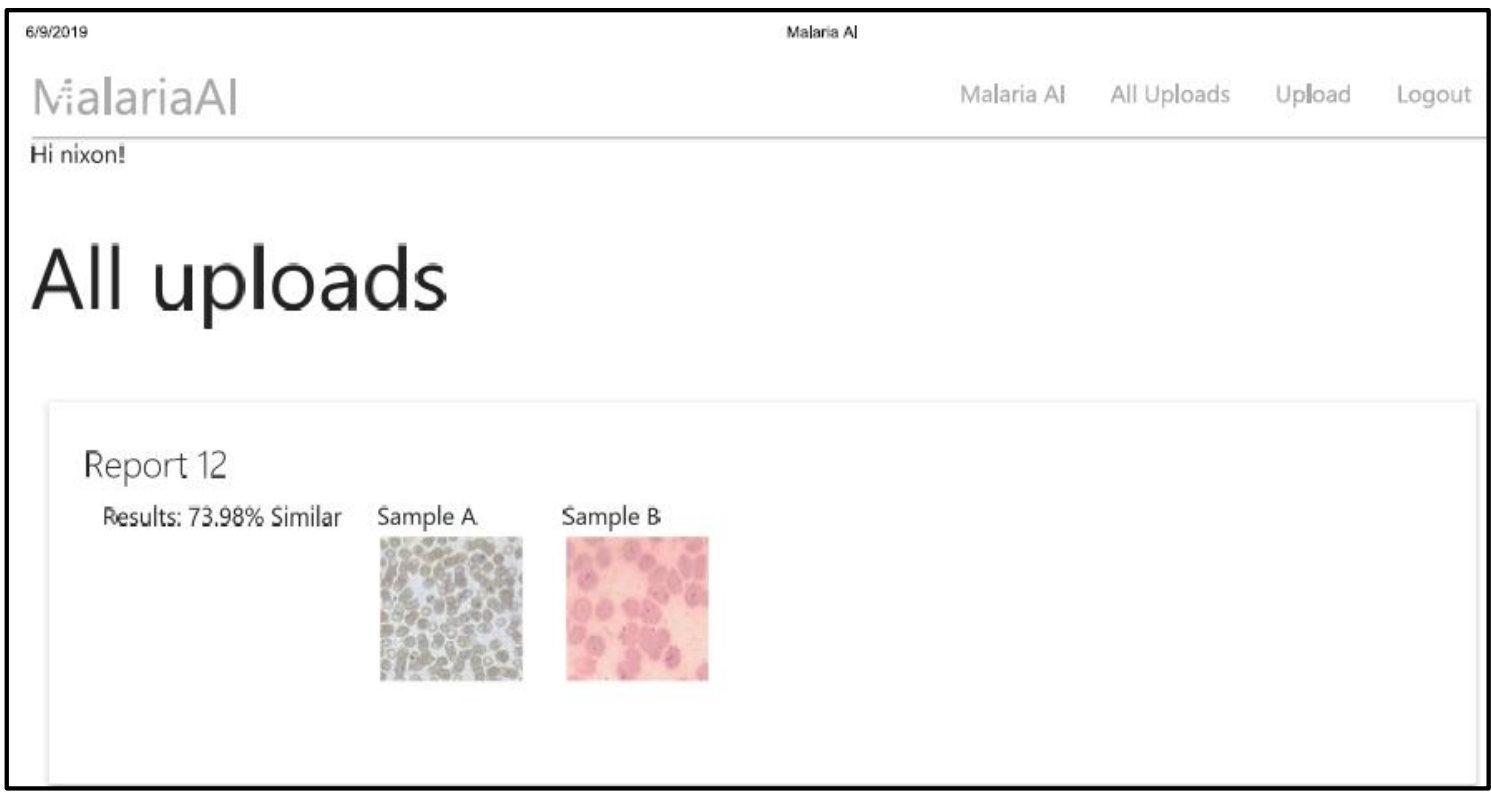

Figure 5 below shows a comparison of two specimen images which are slightly similar. The analysis of the two samples for similarity is $94.1 \%$, meaning the two specimens are almost similar as per the AI algorithms used. this means sample B is positive assuming sample A was the benchmark.

Figure 5: Comparison of two medical images for similarity - B

\section{Report 10}

\section{Fiesults: $94.1 \%$ Similar}
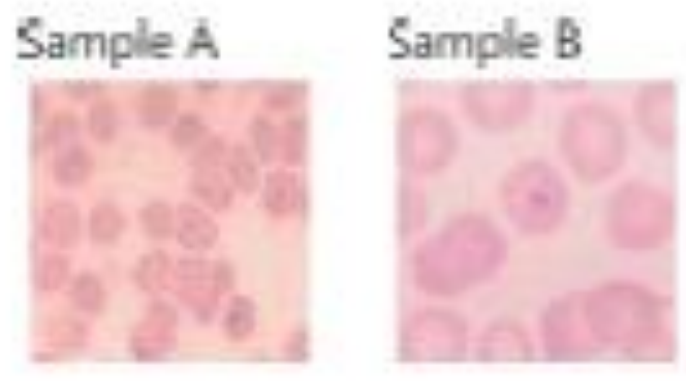

The above mobile application prototype has shown that given a robust medium of communication such as $5 \mathrm{G}$, telemedicine and other eHealth tools will be possible. A study by Market Research Future indicates that telemedicine market will grow at a compound annual rate of about $17 \%$ through the year 2023. 5G technology will enable health providers to transmit massive files from X-rays, MRIs, and other medical images. This will enable people and machines to make critical decisions about a patient's health quicker with more information. 


\section{CONCLUSION}

This paper has presented an overview of the evolution of GSM Technologies into 5G and its impact on the emergence of transformative telemedicine applications. It has been reported in many studies that, information communication and technology is one of the ways in which universal health coverage can be enhanced. The use of 5G wireless technology has the capability to transform healthcare sector by augmenting human capacity and reach rapidly by allowing things like resource pooling, virtualization of high-performance systems of telemedicine and several internet of things (IoT) tools. 5G characteristics such as broadband, low latency and ubiquitous access, will enable integrations of patients and medical practitioners through ICT innovations.

With the new terminal devices, such as smartwatches, wearables, virtual reality devices, smartphones and tablets, patient's habits and expectations are likely to change in view of the interactive nature of the media devices. The need to deliver healthcare services anywhere, anyhow and anytime as opposed to patients moving physically to health facilities is likely to gain momentum with faster internet speeds of $5 \mathrm{G}$ networks.

\section{ACKNOWLEDGEMENTS}

Many thanks to my computer science student (Blair Tsuma) for co-developing the malaria mobile application software.

\section{REFERENCES}

Appiah, D., Ozuem, W., \& Howell, K. E. (2019). Disruptive technology in the smartphones industry: identity theory perspective. In Leveraging Computer-Mediated Marketing Environments (pp. 351-371). IGI Global.

Brandling-Bennett, H. A., Kedar, I., Pallin, D. J., Jacques, G., Gumley, G. J., \& Kvedar, J. C. (2005). Delivering health care in rural Cambodia via store-and-forward telemedicine: a pilot study. Telemedicine Journal \& $e$ Health, 11(1), 56-62.

Christensen, C. M. (2013). The Innovators Dilemma: When New Technologies Cause
Great Firms to Fail. Boston: Harvard Business School Press.

Craig, J., \& Petterson, V. (2005). Introduction to the practice of telemedicine. Journal of telemedicine and telecare, 11(1), 3-9.

Crock, E., 2016, 'Access to healthcare services for people living with HIV experiencing homelessness? A literature review', Australian Journal of Advanced Nursing 34(1), 42-51.

Croteau, A.M.; Vieru, D.; Kifle, M.; and Mbarika V. (2005). An Empirical Assessment of Telemedicine Adoption in the Developing Versus Developed World: The Case of Ethiopia and Canadian Physicians. Submitted to Journal of Management Information System

Gagnon, M. P., Desmartis, M., Labrecque, M., Car, J., Pagliari, C., Pluye, P., ... \& Légaré, F. (2012). Systematic review of factors influencing the adoption of information and communication technologies by healthcare professionals. Journal of medical systems, 36(1), 241-277.

Giovanisa, A. N. and Athanasopouloub, P. (2018). Consumer-Brand Relationships and Brand Loyalty in Technology-Mediated Services. Journal of Retailing and Consumer Services, 40(1), 287-294.

Husenovic, K., Bedi, I. \& Maddens, S. (2018). Setting the Scene for 5G: Opportunities \& Challenges. Geneva, Switzerland: International Telecommunication Union. https://www.itu.int/en/ITUD/Documents/ITU_5G_REPORT-2018.pdf

Justice, E. O. (2012). E-healthcare/telemedicine readiness assessment of some selected states in Western Nigeria. International Journal of Engineering and Technology, 2(2), 195-201.

Kay, M. Santos, J. \& Takane, M. (2010). Telemedicine Opportunities and developments in Member States: Report on the second global survey on eHealth. Global Observatory for eHealth Series - Volume 2. Geneva, Switzerland; World Health Organization 
Khosla, V. (2012, Dec 4). Technology will replace $80 \%$ of what doctors do. Retrieved from Fortune https://fortune.com/2012/12/04/technologywill-replace-80-of-whatdoctors-do, 2012.

Klewes, J., Popp, D. \& Rost-Hein, M. (2017). Outthinking Organizational Communications: The Impact of Digital Transformation. Basel: Springer International Publishing.

Li, D. (2019). 5G and intelligence medicine- - how the next generation of wireless technology will reconstruct healthcare? Precision Clinical Medicine, 2(4), 205-208.

Meraj, M., \& Kumar, S. (2015). Evolution of mobile wireless technology from $0 \mathrm{G}$ to 5G. International Journal of Computer Science and Information Technology, 6(3), 2545-2551.

MOMS \& MOPHS. (2011). Kenya national eHealth strategy_2011-2017. Nairobi, KE: Ministry of Medical Services (MOMS) \& Ministry of Public Health and Sanitation (MOPHS).

http://www.isfteh.org/files/media/kenya_natio nal_ehealth_strategy_2011-2017.pdf:

Norris, S., \& Morgan, R. (2002). Providers issue brief: telehealth: yearend report-2002. Issue brief (Health Policy Tracking Service), 1.

Pal, A., Mbarika, V. W. A., Cobb-Payton, F., Datta, P., \& McCoy, S. (2005). Telemedicine diffusion in a developing country: the case of India (March 2004). IEEE Transactions on Information Technology in Biomedicine, 9(1), 59-65.

Sodhro, A. H., \& Shah, M. A. (2017, April). Role of 5G in medical health. In 2017 International Conference on Innovations in Electrical Engineering and Computational Technologies (ICIEECT) (pp. 1-5). IEEE. https://ieeexplore.ieee.org/abstract/document/7 916586

Strehle, E. M., \& Shabde, N. (2006). One hundred years of telemedicine: does this new technology have a place in paediatrics.
Archives of disease in childhood, 91(12), 956959.

Valenduc, G., \& Vendramin, P. (2017). Digitalisation, between disruption and evolution. Transfer: European Review of Labour and Research, 23(2), 121-134.

Watts, C., \& Ibegbulam, I. (2006). Access to electronic healthcare information resources in developing countries: Experiences from the Medical Library, College of Medicine, University of Nigeria. IFLA Journal, 32(1), 5461.

WHO 2006 report: Working together for health. Available at https://apps.who.int/iris/bitstream/handle/1066 5/43432/9241563176_eng.pdf;jsessionid=171 E2782A4FFAECAB0ABB8281FADF388?seq uence $=1$

WHO 2010 Global Observatory for eHealth Series, 2: Available at: https://www.who.int/goe/publications/goe_tele medicine_2010.pdf

Xue, Y., \& Liang, H. (2007). Analysis of telemedicine diffusion: the case of China. IEEE transactions on information technology in biomedicine, 11(2), 231-233. 